\title{
INTERACTIONS OF LISTERIA MONOCYTOGENES, LISTERIA SEELIGERI, AND LISTERIA INNOCUA WITH PROTOZOANS
}

\author{
THI MINH CHAU LY AND HANS E. MÜLLER* \\ Staatliches Medizinaluntersuchungsamt, Hallestr. 1, D-3300 Braunschweig, FRG
}

(Received March 19, 1990)

\begin{abstract}
Cocultures of three Listeria species, L. monocytogenes, L. seeligeri, and L. innocua with Acanthamoeba castellanii, and Tetrahymena pyriformis, respectively, were investigated. The Listeria were ingested intracellularly by the protozoans. However, they were not killed, on the contrary, they survived. The two hemolytic Listeria species, i.e. L. monocytogenes and L. seeligeri ruptured their host cells completely after a few days and became free. Subsequently, they died.

On the other hand, the apathogenic L. innocua partially lysed the protozoans and coexisted intracellularly as well as extracellularly for some weeks. Additionally, cocultures of L. monocytogenes, Escherichia coli, Salmonella typhimurium, and A. castellanii, T. pyriformis, respectively, were studied. The results showed that both protozoans possess similar distinct preferences for the Salmonella and Listeria, but E. coli was not desirable 'prey.' Ingested S. typhimurium were killed but L. monocytogenes survived.

The observed phenomena provide a special insight regarding $L$. monocytogenes infection in man and animals in respect to the different behaviour patterns of the three Listeria species investigated.
\end{abstract}

Many observations suggest that species of the genus Listeria are considered soil microorganisms $(19,20)$. Notwithstanding, L. monocytogenes is the causative agent of listeriosis that affects humans as well as many species of mammals and birds $(11,12)$. Of course, some other Listeria species which have recently been described, show similar biochemical and ecological properties but they are nonpathogenic.

The virulence of $L$. monocytogenes seems to be related to its intracellular multiplication in host cells. However, it is puzzling how saprophytic soil bacteria

* Address reprint requests to: Prof. Dr. Hans E. Müller, Staatl. Medizinaluntersuchungsamt, Hallestr. 1, D-3300 Braunschweig, FRG. 
have or acquire the ability to survive and multiply within cells of warm-blooded hosts. Lower animals are not considered because Listeria species normally do not exist in such hosts, as a previous publication has shown (12). Therefore, we examined the hypothesis that amebas or other free-living protozoans can serve as natural hosts to Listeria because they have properties similar to the macrophages of warm-blooded hosts in which L. monocytogenes multiplies.

\section{MATERIALS AND METHODS}

Bacteria. L. monocytogenes, strain L119, L. seeligeri, strain L106, and L. innocua, strain L118, were isolated from waste-water and characterized biochemically and serologically as described in previous papers $(5,6)$.

Escherichia coli and Salmonella typhimurium were freshly isolated from human feces. Their biochemical and serological characteristics were tested according to standard procedures $(3,4,9)$.

Protozoa. Acanthamoeba castellanii was isolated from fresh water by filtration through cellulosic nitrate membranes with a pore size of $3 \mu \mathrm{m}$ (SM 11302, Sartorius, Göttingen, FRG). The filters were placed on non-nutrient agar plates spread with a $0.1-\mathrm{ml}$ suspension of heat-killed $E$. coli $\left(10^{8} \mathrm{CFU} / \mathrm{ml}\right)$. The plates were incubated at about $20^{\circ} \mathrm{C}$ for 1 week in a moist chamber. Differentiation was performed according to appropriate keys $(8,13,22)$. They were maintained non-nutrient agar as described above.

Tetrahymena pyriformis was from a stock strain grown in Diamond's medium $(8)$ at $20^{\circ} \mathrm{C}$. The cells were collected by filtering through $3 \mu \mathrm{m}$ filters of cellulosic nitrate membranes. They were washed and suspended in sterile tap water.

Counting. Amoebae were enumerated by adding $0.1 \mathrm{ml}$ of the suspension of protozoans to $0.1 \mathrm{ml}$ of a $0.005 \%$ solution of methylene blue and counting the number of cells in a Neubauer chamber $\left(0.1 \times 0.0025 \mathrm{~mm}^{2}\right)$ using bright-field illumination at $10 \times$ magnification. Each counting was performed twice and the average counts were recorded.

T. pyriformis were enumerated by adding $0.1 \mathrm{ml}$ of the protozoans to $0.05 \mathrm{ml}$ of Türk's solution (acetic acid gentian violet solution) and $0.05 \mathrm{ml}$ distilled water. The counting was performed in a Neubauer chamber as described above.

Listeria were enumerated by plating and counting CFUs on an acriflavineceftazidine agar plate incubated at $30^{\circ} \mathrm{C}(1,2)$. E. coli and $S$. typhimurium were plated and counted on MacConkey agar $(3,9)$. All plates were prepared in duplicate with different dilutions. Only plates with 30 to 300 colonies were counted. The bacterial counts per $\mathrm{ml}$ were computed by multiplying the average number of colonies per plate by dilution used.

Microscopy. A. castellanii were examined by a suspension in one drop of sterile tap water on a cover slip using Zeiss Axioscope. T. pyriformis were examined microscopically in situ in Petri dishes with a Zeiss stereomicroscope DR.

All preparations of protozoans having ingested Listeria were tested for viability 
of the intracellular bacteria by a fluorescent staining procedure using fluorescein diacetate $(7,15)$.

Determination of phagocytosis of Listeria by protozoans. A. castellanii, and $T$. pyriformis, respectively, fed in cocultures with Listeria were separated at different times from extracellular Listeria by filtration and washed for $1 \mathrm{~h}$ with a solution of gentamicin $(0.5 \mu \mathrm{g} / \mathrm{ml})$ and then three times with $100 \mathrm{ml}$ of sterile tap water. Thereafter, the washed protozoans were suspended and no extracellular viable Listeria was detected. The disruption of the protozoans was performed by ultrasonication for $10 \mathrm{~s}$. The complete disintegration of protozoans was confirmed by a microscopic examination and no loss of viability of Listeria occurred under these conditions. Portions of lysed suspensions were plated on acriflavine-ceftazidine agar plates and Listeria CFUs were counted. Survival curves were drawn by plotting the $\log 10$ number of survivors against time.

Cocultivation experiments. Each experiment consisted of three tests:

(a) a pure suspension of $A$. castellanii or $T$. pyriformis in sterile tap water as controls,

(b) a pure suspension of Listeria spec., E. coli, S. typhimurium, respectively, in sterile tap water as controls, and

(c) the coculture. equal volumes $(25 \mathrm{ml})$ of appropriate concentrations of organisms suspended in sterile tap water were mixed, incubated at $36^{\circ} \mathrm{C}$ up to 5 weeks, and investigated as described above.

All experiments were performed repeatedly. The figures are typical and reproducible regarding the course of graphs. However, the data obtained from different assays were not suitable for a summarizing statistical presentation.

\section{RESULTS}

Sequential counts of coculture suspensions of $A$. castellanii infected with $L$. monocytogenes, L. seeligeri or L. innocua are given in Fig. 1. As the controls show in Fig. 3, the Listeria died within 18 to 34 days and the number of amoebas decreased. Of course, later they encysted and the counts remained constant. The behaviour of amoebas in the three cocultures was more or less the same. The numbers rose to a maximum after 1 week, decreased slightly and remained constant as cysts. The three Listeria species showed a similar behaviour only in the first week. Their extracellular level decreased by 7 to 8 orders of magnitude. But after that time, L. monocytogenes, and L. seeligeri disappeared completely from the extracellular compartment. Thereafter, the counts rose by 3 to 5 orders of magnitude and then decreased again. In contrast, after an initial fall the number of L. innocua remained constant over 4 weeks. The number and fate of ingested and intracellular Listeria were similar in the three cocultures with $A$. castellanii. After the first few days, the amoebas contained hundreds of living listerias intracellularly as shown by fluorescein diacetate. In about the second week, some of the amoebas ruptured and set free listerias, recognizable because of the increasing counts of extracellular 

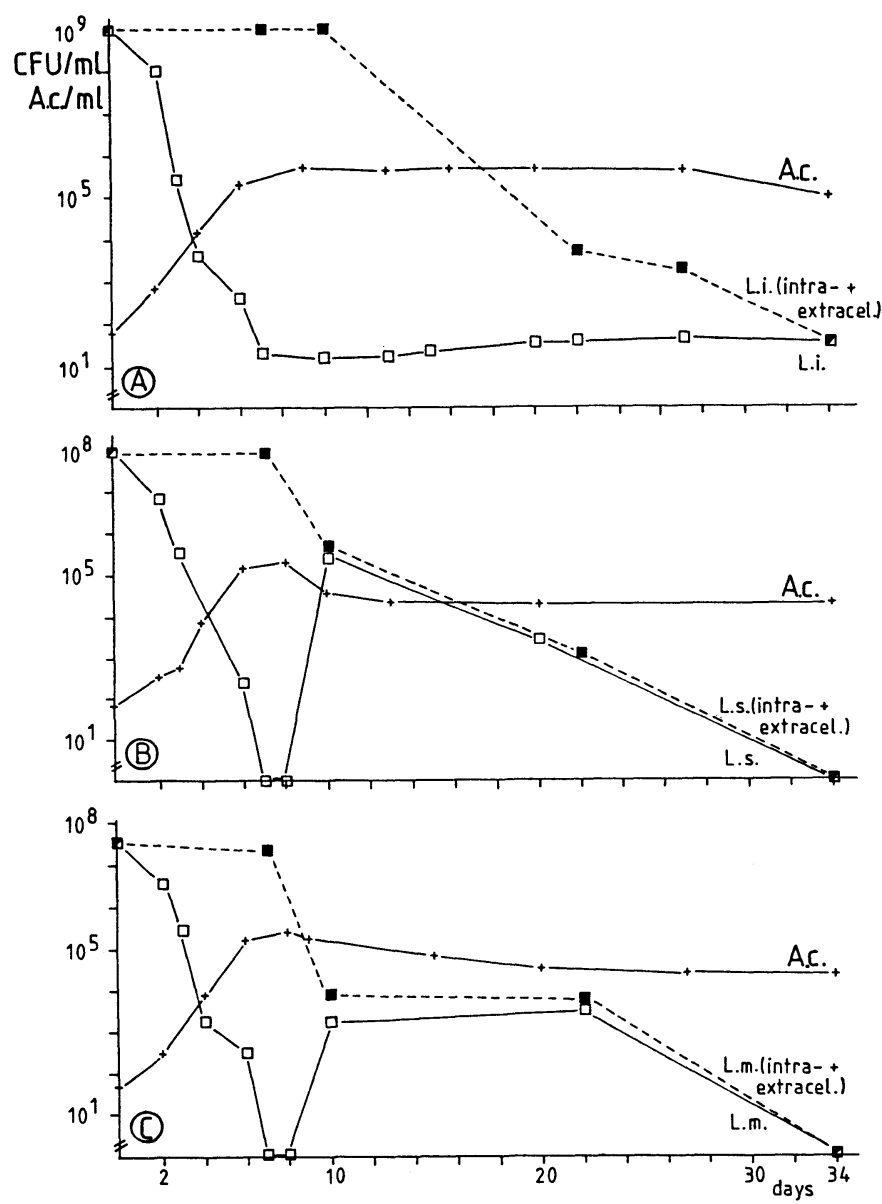

Fig. 1. Cocultures of Acanthamoeba castellanii (A.c.) with A) Listeria innocua (L.i.), B) Listeria seeligeri (L.s.), and C) Listeria monocytogenes (L.m.). The dotted lines give the concentrations $(\mathrm{CFU} / \mathrm{ml})$ of intra- and extracellular listerias in toto. The stretched lines represent only the extracellular organisms.

L. monocytogenes, or L. seeligeri. But L. innocua were not released and remained constant at low counts extracellularly. Most of the amoebas developed cysts, and, synchronously, the Listeria ingested were destroyed (Fig. 1).

The cocultures with $T$. pyriformis are given in Fig. 2. In contrast to amoebas, T. pyriformis do not develop cysts. Of course, they multiply abundantly in the presence of Listeria sp. by increasing the cell number by about 3 orders of magnitude due to fission into small cells. In a manner similar to coculture with $A$. castellanii, the concentration of listerias decreased in coculture with $T$. pyriformis, and reached zero after about 6 days in the cases of L. monocytogenes and L. seeligeri, whereas low concentrations of $L$. innocua remained detectable extracellularly. $T$. pyriformis cells 

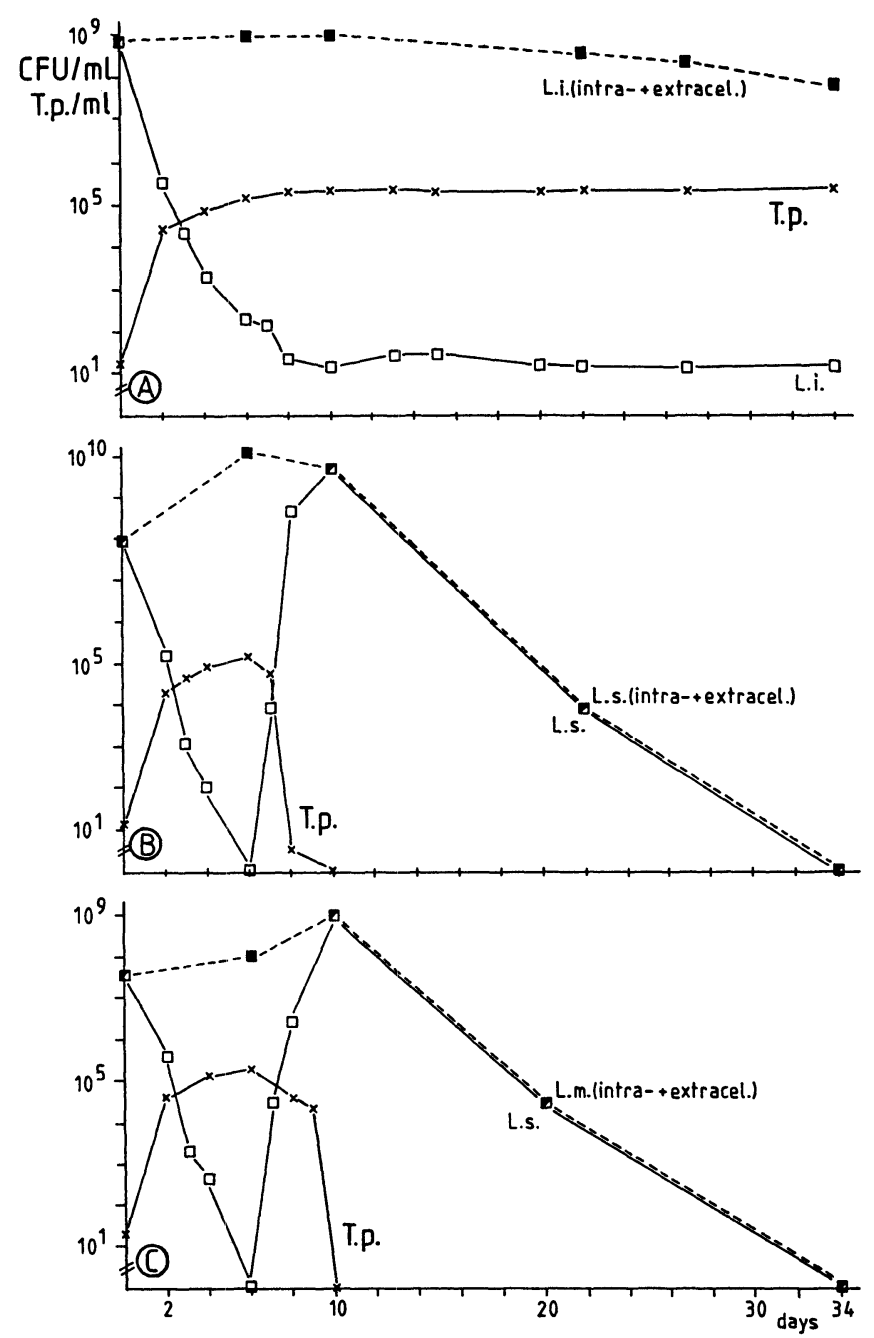

Fig. 2. Cocultures of Tetrahymena pyriformis (T.p.) with A) Listeria innocua (L.i.), B) Listeria seeligeri (L.s.), and C) Listeria monocytogenes (L.m.). The dotted lines give the concentrations $(\mathrm{CFU} / \mathrm{ml})$ of intra- and extracellular listerias in toto. The stretched lines represent only the extracellular organisms.

having phagocytized $L$. monocytogenes and $L$. seeligeri, began to lyse and after a further 1 to 2 weeks, they disappeared and were seen no more. To the same extent listerias became free and were detectable extracellularly. As rupture experiments showed, each $T$. pyriformis cell contained about $6-9 \times 10^{3}$ listerias. But notwithstanding that $T$. pyriformis contained so many $L$. innocua, only a few of the host cells ruptured and released $L$. innocua. Up to day 33 , concentrations of $T$. pyriformis cells, of $L$. innocua extracellular as well as intracellular within 


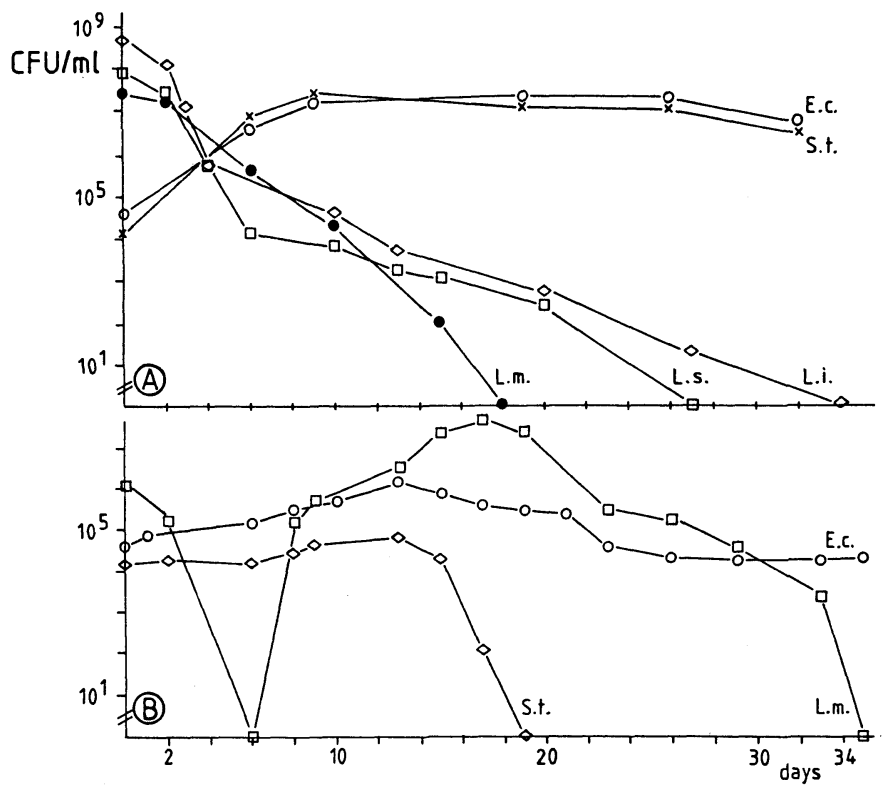

Fig. 3. A) The behaviour patterns of pure suspensions of bacteria as controls without protozoans: Escherichia coli (E.c.), Salmonella typhimurium (S.t.), Listeria innocua (L.i.), Listeria seeligeri (L.s.), and Listeria monocytogenes (L.m.). B) Cocultures of Tetrahymena pyriformis with three bacterial species: Escherichia coli (E.c.), Listeria monocytogenes (L.m.), and Salmonella typhimurium (S.t.).

T. pyriformis remained constant, as Fig. 2 shows.

In a further set of experiments, cocultures with protozoans, L. monocytogenes and two additional bacterial species, i.e. E. coli and S. typhimurium, were investigated (Fig. 3). Both, L. monocytogenes and S. typhimurium were prefered 'prey' for both protozoans and their counts dropped during the first week. While $S$. typhimurium disappeared completely between days 17 and 19, L. monocytogenes showed increasing cell counts after the first week due to the rupture of protozoans. However, E. coli did not show this phenomenon. Its concentrations remained nearly constant.

\section{DISCUSSION}

Regarding the three Listeria species, there are significant differences in the behaviour patterns of the cocultures analogous to their pathogenicity. The most pathogenic L. monocytogenes as well as the 'apathogenic' but hemolytic L. seeligeri lysed their host cells. Even a multiplication occurred in T. pyriformis. In this context, it is worthwhile to note that $L$. seeligeri possess pathogenic potential to some extent, as patient with meningitis due to L. seeligeri showed (16). Obviously, hemolysin is an important virulence factor $(10,14)$ which may also be due to the ability to rupture the protozoans. In contrast, L. innocua is apathogenic and non-hemolytic. 
The microorganisms were ingested and survived within protozoans. They were killed by $A$. castellanii only while encystment occured. However, a transient coexistence of $T$. pyriformis and L. innocua lasted for 5 weeks. As the experiments of cocultures of protozoans with three different bacterial species showed, $A$. castellanii and $T$. pyriformis have the same distinct preferences for Listeria and Salmonella, two species which also have the ability to survive intracellularly in warm-blooded hosts. E. coli, however, was phagocytized to a lesser degree.

The ecological niche of listerias was seen up to now to be in soil and mud $(19,20)$. However, they seem to be not only saprophytic organisms, but are also intracellular parasites of protozoans. L. innocua seem to be adapted best to their phagocytizing hosts, because they are able to coexist with and in protozoans for a longer period of time. But L. monocytogenes and L. seeligeri are more pathogenic for protozoans as well as mammals and human beings. Especially, L. monocytogenes are able to survive and multiply inside numerous host cells, i.e. macrophages and, furthermore, in enterocytes or hepatocytes $(11,19,20)$. This property seems to be to related to the lysis of protozoans. Of course, it is unclear up to now whether the hemolysin is the responsible factor for both effects. However, the phenomenon of survival within and rupture of protozoans provides a special insight into an obviously general principle: facultative pathogenic water and soil bacteria, with ecological niches in the environment and the ability to multiply intracellularly in host cells, have probably acquired this property in protozoans. Some years ago, Rowbotham reported that legionellas ingested by amebas multiply intracellularly and then rupture them $(17,18)$. Now listerias are a further example. Supposedly, other pathogens living in the environment and proliferating intracellularly have acquired the virulence for humans in a similar manner by means of their ability to survive and multiply within protozoans, i.e. Mycobacterium leprae, ubiquitous atypical nontuberculous mycobacteria, or Yersinia species.

More knowledge is needed to understand the ecological niches for such microorganisms and the correlations with virulence and pathogenicity for warm-blooded hosts.

This project was supported by the German Bundesanstalt für Arbeit (ABM-No. 96/87/211). We thank Sabine Müller and Friederike Heimbach for excellent technical assistance.

\section{REFERENCES}

1) Bannerman, E. S. and Bille, J., A new selective medium for isolating Listeria spp. from heavily contaminated material. Appl. Environ. Microbiol., 54, 165-167 (1988).

2) Curtis, G. D. W., Nichols, W. W., and Falla, T. J., Selective agents for Listeria can inhibit their growth. Lett. Appl. Microbiol., 8, 169-172 (1989).

3) Ewing, W. H., Identification of Enterobacteriaceae, 4th ed., Elsevier Publ., New York, Amsterdam, Oxford (1986).

4) Farmer, J. J. III, Davis, B. R., Hickman-Brenner, F. W., McWhorter, A., Huntley-Carter, G. P., Asbury, M. A., Riddle, C., Wathen-Grady, H. G., Elias, C., Fanning, G. R., Steigerwalt, A. G., O'Hara, C. M., Morris, G. K., Smith, P. B., and Brenner, D. J., Biochemical identification of new 
species and biogroups of Enterobacteriaceae isolated from clinical specimens. J. Clin. Microbiol., 21, 46-76 (1985).

5) Geuenich, H.-H. and Müller, H. E., Isolierung •und Keimzahlbestimmung von Listeria monocytogenes in ungeklärtem und biologisch gereinigtem Abwasser. Zentralbl. Bakteriol. Parasitenkde. Infektionskr. Hyg., Abt. 1: Orig. B, 179, 266-273 (1984).

6) Geuenich, H.-H., Müller, H. E., Schrettenbrunner, A., and Seeliger, H. P. R., The occurrence of different Listeria species in municipal waste water. Zentralbl. Bakteriol. Parasitenkde. Infektionskr. Hyg., Abt. 1: Orig. B, 181, 563-565 (1985).

7) Kvach, J. T. and Veras, J. R., A fluorescent staining procedure for determining the viability of mycobacterial cells. Int. J. Leprosy, 50, 183-192 (1982).

8) Lee, J. J., Hutner, S. H., and Bovee, E. C., An Illustrated Guide to the Protozoa, Society of Protozoologists, Lawrence, Kansas (1985).

9) Lennette, E. H., Balows, A., Hausler, W. H. Jr., and Shadomy, H. H., Manual of Clinical Microbiology, 4th ed., ASM, Washington D.C. (1985).

10) Mengaud, J., Chenevert, J., Geoffroy, C., Gaillard, J. L., and Casart, P., Identification of the structural gene coding the $\mathrm{SH}$-activated hemolysin of Listeria monocytogenes: listeriolysin $\mathrm{O}$ is homologous to streptolysin O and pneumolysin. Infect. Immun., 55, 3225-3227 (1987).

11) Müller, H. E., Listeriosis in animals. Infeksiyon Dergisi (Turkish J. of Infection), 2, 505-519(1988).

12) Müller, H. E., Absence of Listeria monocytogenes in lower animals. Ann. Inst. Pasteur, Microbiol., 139, 727-730 (1988).

13) Page, F. C., An Illustrated Key to Freshwater and Soil Amoebae, Freshwater Biological Assoc., Scientific Publ. No. 34, Ferry House, Ambleside, Cumbria, GB (1976).

14) Parrisius, J., Bhakdi, S., Tranum-Jensen, J., Goebel, W., and Seeliger, H. P. R., Production of listeriolysin by beta-hemolytic strains of Listeria monocytogenes. Infect. Immun., 51, 314-319(1986).

15) Paton, A. M., Jones, S. M., The observation and enumeration of microorganisms in fluids using membrane filtration and incident fluorescence microscopy. J. Appl. Bacteriol., 38, 199-200 (1975).

16) Rocourt, J., Hof, H., Schrettenbrunner, A., Malinverni, R., and Bille, J., Méningite purulente aigue à Listeria seeligeri chez un adult immunocompétent. Schweiz. Med. Wschr., 116, 248-251 (1986).

17) Rowbotham, J., Preliminary report on the pathogenicity of Legionella pneumophila for freshwater and soil amoebae. J. Clin. Pathol., 33, 1178-1183 (1980).

18) Rowbotham, J., Current views on the relationships between amoebae, legionella and man. Israel J. Med. Sci., 22, 678-689 (1986).

19) Seeliger, H. P. R., Why listeriosis? Infeksiyon Dergisi (Turkish J. of Infection), 2, 455-460 (1988).

20) Seeliger, H. P. R., Listeriosis-history and actual developments. Infection, 16, 580-584 (1988).

21) Seeliger, H. P. R. and Jones, D., Genus Listeria Pirie 1940, 383 ${ }^{\mathrm{AL}}$. In Bergeys Manual of Systematic Bacteriology, Vol. 2, ed. by Sneath, P. H. A., Mair, N. S., Sharpe, M. E., and Holt, J. G., Williams \& Wilkins, Baltimore, London, Los Angeles, Sydney (1986), p. 1235-1245.

22) Streble, H. and Krauter, D., Das Leben im Wassertropfen. Mikroflora und Mikrofauna des Süßwassers. Frankh, Stuttgart, FRG (1973). 